\title{
Modelo teórico de empresarialidad rural y su influencia en la competitividad de las mipymes
}

\author{
Theoretical Model of Rural Entrepreneurship and Its Influence on the \\ Competitiveness of MSMEs
}

\section{Modelo teórico de empreendedorismo rural e sua influência na competitividade das MPMEs}

\author{
Alma Delia Inda \\ Universidad Autónoma de Baja California, México \\ alma.inda@uabc.edu.mx \\ https://orcid.org/0000-0003-1519-586X \\ Gloria Muñoz del Real \\ Universidad Autónoma de Baja California, México \\ gloria.munoz@uabc.edu.mx \\ https://orcid.org/0000-0002-7694-162X \\ Olga Lidia Gutierrez Gutierrez \\ Universidad Autónoma de Baja California, México \\ olgagutierrez@uabc.edu.mx \\ https://orcid.org/0000-0001-8167-2682
}

\section{Resumen}

Este estudio propone un modelo teórico de empresarialidad rural que se analiza a través del modelo nacional para las mipymes competitivas presentado por el Instituto para el Fomento a la Calidad Total [IFCT] (2010). El objetivo consiste en determinar si la planeación estratégica contribuye sobre la empresarialidad de las empresas rurales, así como en medir el grado de influencia que la empresarialidad tiene sobre las actividades de alianzas estratégicas, relación con sus clientes y recursos humanos. El método que se utilizó fue de corte cuantitativo, no experimental, de tipo transversal. El sujeto de estudio fueron las mipymes 


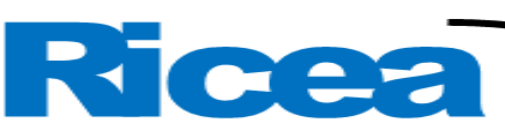

REVISTA IBEROAMERICANA DE CONTADURÍA, ECONOMÍA YADMINISTRACIÓN

ISSN $=2007-9907$

del medio rural del valle de Mexicali, Baja California, México. Para el análisis estadístico, se aplicó el método multivariante de segunda generación denominado modelación de ecuaciones estructurales con mínimos cuadrados parciales (PLS-SEM). El modelo estructural presentó como resultado que la variable dependiente Empresarialidad sí es influenciada por la variable independiente Planeación Estratégica, es decir, las acciones de estrategias de mercado, infraestructura, innovación de nuevos productos y mercados, así como imagen empresarial, sí influyen en el proceso de empresarialidad, particularmente en el plan de sucesión, comunicación empresa-familia y la integración de trabajadores-familia. De igual manera, cuando las empresas familiares del medio rural desarrollan su empresarialidad, esta ejerce influencia sobre la generación de alianzas estratégicas, relación con sus clientes y su integración del recurso humano, lo que significa que una mipyme del medio rural debe adoptar acciones de planeación para que su competitividad se vea fortalecida.

Palabras clave: competitividad, empresarialidad rural, empresas familiares, planeación estratégica

\section{Abstract}

This study proposes a theoretical model of rural entrepreneurship that is analyzed through the national model for competitive MSMEs presented by the Instituto para el Fomento a la Calidad Total [IFCT] (2010). The objective is to determine if strategic planning contributes to the entrepreneurship of rural companies, as well as to measure the degree of influence that entrepreneurship has on the activities of strategic alliances, relationships with their clients and human resources. The method used was quantitative, non-experimental, cross-sectional. The study subject was the MSMEs from the rural environment of the Mexicali Valley, Baja California, Mexico. For the statistical analysis, the second generation multivariate method called partial least squares structural equation modeling (PLS-SEM) was applied. The structural model presented as a result that the dependent variable Entrepreneurship is influenced by the independent variable Strategic Planning, that is, the actions of market strategies, infrastructure, innovation of new products and markets, as well as business image, do influence the process of entrepreneurship, particularly in the succession plan, companyfamily communication and the integration of workers-family. Similarly, when family businesses in rural areas develop their entrepreneurship, this exerts influence on the 


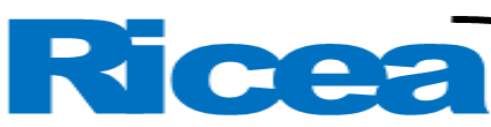

REVISTA IBEROAMERICANA DE CONTADURÍA, ECONOMÍA YADMINISTRACIÓN

ISSN= $2007-9907$

generation of strategic alliances, relationships with their clients and their integration of human resources.

Keywords: competitiveness, rural entrepreneurship, family businesses, strategic planning.

\section{Resumo}

Este estudo propõe um modelo teórico de empreendedorismo rural que é analisado por meio do modelo nacional de MPMEs competitivas apresentado pelo Instituto para a Promoção da Qualidade Total [IFCT] (2010). O objetivo é verificar se o planejamento estratégico contribui para o empreendedorismo das empresas rurais, bem como medir o grau de influência que o empreendedorismo exerce sobre as atividades de alianças estratégicas, relacionamento com seus clientes e recursos humanos. O método utilizado foi quantitativo, não experimental, transversal. O sujeito do estudo foram as MPMEs do meio rural do Vale Mexicali, Baja California, México. Para a análise estatística, foi aplicado o método multivariado de segunda geração denominado modelagem de equações estruturais de mínimos quadrados parciais (PLS-SEM). O modelo estrutural apresentou como resultado que a variável dependente Empreendedorismo é influenciada pela variável independente Planejamento Estratégico, ou seja, as ações de estratégias de mercado, infraestrutura, inovação de novos produtos e mercados, bem como a imagem do negócio, influenciam no processo de o empreendedorismo, nomeadamente no plano de sucessão, a comunicação empresa-família e a integração trabalhadores-família. Da mesma forma, quando as empresas familiares do meio rural desenvolvem seu empreendedorismo, este exerce influência na geração de alianças estratégicas, relacionamento com seus clientes e sua integração de recursos humanos, o que significa que uma MPME no meio rural deve adotar ações de planejamento para que sua competitividade seja fortalecido.

Palavras-chave: competitividade, empreendedorismo rural, empresas familiares, planejamento estratégico.

Fecha Recepción: Mayo 2020 Fecha Aceptación: Diciembre 2020 


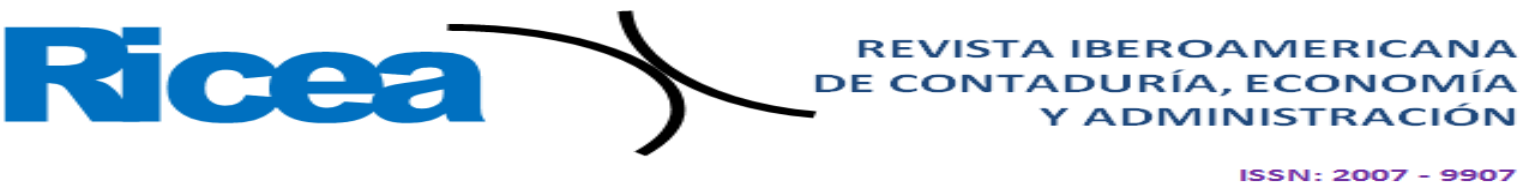

\section{Introducción}

Las micro, pequeñas y medianas empresas (mipymes) en México representan $99.8 \%$ del total de las unidades económicas del país, generan $78.5 \%$ del empleo y además aportan $52 \%$ del producto interno bruto (PIB), según Saavedra y Saavedra (2014). La producción rural es parte fundamental del aporte económico, debido a que el tejido de la cadena de valor que se conforma promueve la generación de empresas familiares. Para el Instituto del Fomento a la Calidad Total [IFCT] (2010), las mipymes deben integrarse, a través del modelo nacional para las mipymes competitivas (ver figura 1), a la cadena de valor de su actividad preponderante, sean estas del medio urbano o rural.

Baja California es un estado que concentra un número importante de población rural. Esta condición implica la formación de negocios en cada una de las comunidades rurales. Según el Programa Sectorial de Desarrollo Económico 2009-2013 (Mungaray, 2019), existen 4511 poblados o localidades rurales en Baja California, que representan $8 \%$ del total de la población. Sin embargo, la débil formación empresarial de estos negocios rurales conduce a organizaciones poco profesionales, falta de planeación en la sucesión y debilidad en la administración provocada por la ausencia de una comunicación efectiva, condiciones que pudieran ser mejoradas a través del desarrollo de la planeación estratégica para promover la competitividad y el crecimiento económico.

Teniendo en cuenta lo anterior, el modelo teórico de empresarialidad rural aquí propuesto tiene como objetivo determinar si la planeación estratégica contribuye sobre la empresarialidad de las empresas rurales y medir el grado de influencia que la empresarialidad tiene sobre las actividades de alianzas estratégicas, relación con sus clientes y recursos humanos. Las hipótesis plantean la influencia que una variable ejerce sobre otra:

- $\quad \mathrm{H}_{1}$ : Planeación Estratégica $\rightarrow$ Empresarialidad;

- $\quad \mathrm{H}_{2}$ : Empresarialidad $\rightarrow$ Alianzas Estratégicas;

- $\quad \mathrm{H}_{3}$ : Empresarialidad $\rightarrow$ Relación con los Cliente;

- $\quad \mathrm{H}_{4}$ : Empresarialidad $\rightarrow$ Recursos Humanos;

- $\quad \mathrm{H}_{5}$ : Alianzas Estratégica $\rightarrow$ Relación con los Clientes;

- $\quad \mathrm{H}_{6}$ : Relación con los Clientes $\rightarrow$ Recursos Humanos, y

- $\quad \mathrm{H}_{7}$ : Planeación Estratégica $\rightarrow$ Recursos Humanos (ver figura 2).

El método de análisis empleado fue de corte cuantitativo. El programa SmartPLS versión 3.2.8 fue utilizado como herramienta de apoyo. La población objeto de estudio fueron 


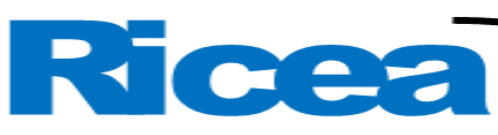

REVISTA IBEROAMERICANA DE CONTADURÍA, ECONOMÍA YADMINISTRACIÓN

ISSN= $2007-9907$

empresarios dedicados al comercio, servicio y producción de ganado en especies menores localizados en Ciudad Morelos, poblado ubicado dentro del valle de Mexicali, Baja California, México. El instrumento para la recopilación de datos fue una encuesta con escala Likert.

\section{Marco teórico}

Este apartado aborda las teorías de los constructos analizados en el modelo estructural que se desarrolla en esta investigación. La empresarialidad, alianzas estratégicas, relación con los clientes, recursos humanos y planeación estratégica son desglosados teóricamente para la identificación de los indicadores que integran el instrumento de medición aplicado. El análisis teórico va de lo general a lo particular de las empresas familiares del medio rural.

\section{Competitividad}

Esser, Hillebrand, Messner y Meyer (1996) mencionan que la competitividad es el producto de un patrón de interacción compleja y dinámica entre el Estado, las empresas, las instituciones intermedias y la capacidad organizativa de una sociedad. La competitividad de la economía descansa en medidas dirigidas a un objetivo, articuladas en cuatro niveles del sistema: macro, meta, micro y meso, basado en un concepto pluridimensional de conducción (Esser et al.,1996).

Este trabajo aborda el nivel micro. El nivel micro se enfoca en la eficiencia, la calidad, la flexibilidad y la rapidez de reacción por parte de las empresas a través de mejoras en la capacidad de gestión, estrategias empresariales, innovación, prácticas productivas, redes de colaboración, manejo de logística empresarial y una buena interacción con los proveedores, productores y clientes.

El IFCT (2010) propone para las mipymes un modelo que tiene por objeto promover la competitividad a través del desarrollo de las capacidades internas de una empresa, así como de la gestión de los recursos humanos en áreas como el manejo de materiales financieros o de conocimiento empresarial. Este modelo está compuesto de una serie de preguntas que invitan a la reflexión sobre el entorno, la administración, la relación con los clientes, la definición de la propuesta de valor, la formalización de alianzas, la gestión de recursos y actividades claves, el control de fuentes de ingresos, el control de su estructura 


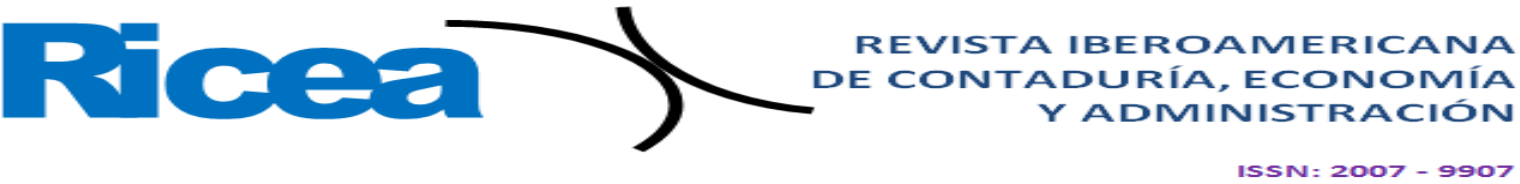

de costos y, finalmente, la medición de los resultados sobre las estrategias implementadas (ver figura 1).

Figura 1. Modelo nacional para las mipymes competitivas

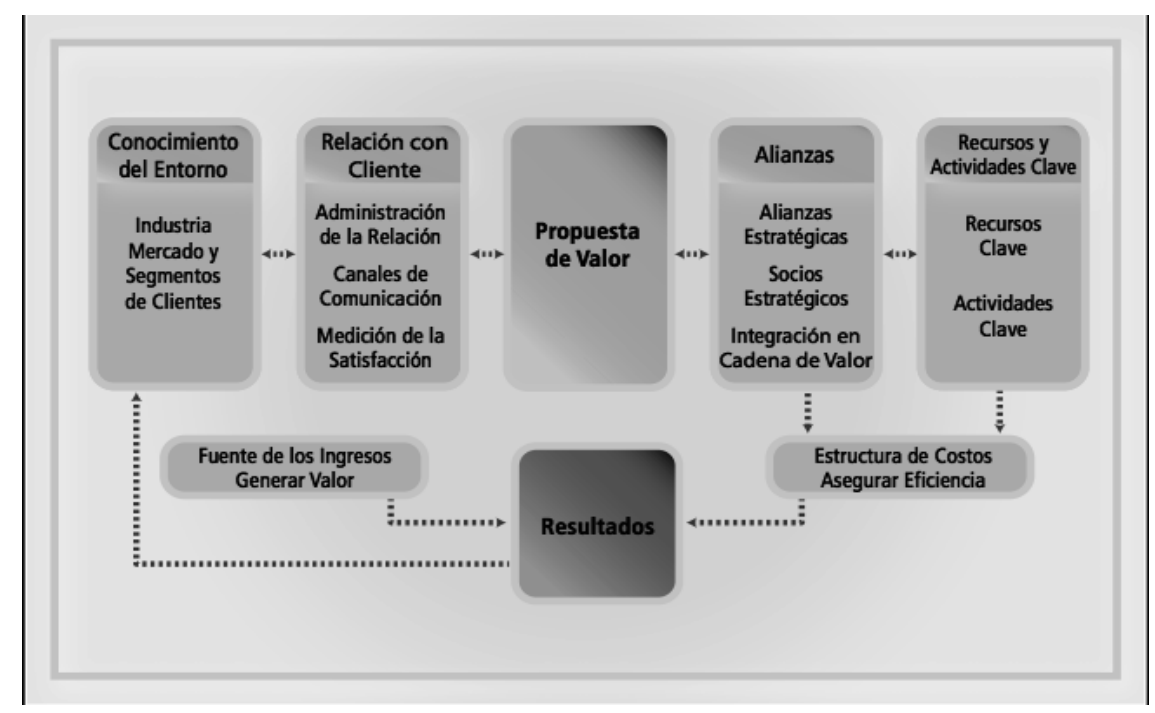

Nota: la imagen muestra que, para promover la viabilidad y competitividad de las mipymes, es necesario que estas conozcan el entorno, la administración de la relación con los clientes, la definición de una propuesta de valor, la generación de alianzas, la gestión de recursos, así como el control de las fuentes de ingresos y su estructura de costos.

Fuente: IFCT (2010)

El modelo en cuestión considera que las mipymes deben encontrar acciones de creación y desarrollo en las áreas específicas de empresarialidad, alianzas, relación con los clientes, recursos humanos y planeación estratégica, entre otras. Sin embargo, existen modelos y acciones específicas de competitividad para las empresas familiares, tal es el caso del modelo 4C propuesto por Miller y Breton (2006). Este modelo resume cuatro objetivos estratégicos que desarrollan las empresas familiares exitosas: continuidad, comunidad, conexión y control. La continuidad se refiere a la sucesión del negocio familiar (en este objetivo se presenta la fidelidad de los integrantes); la comunidad considera al talento humano como el factor diferenciador que potencia la competitividad de una organización, la cual debe ser capacitada y fidelizada; la conexión pretende fortalecer la relación con proveedores, comunidad, clientes y Gobierno a través del beneficio mutuo, y el control se centra en un liderazgo transformacional que no imponga reglas y órdenes, sino que impulse y motive al personal para desarrollar estrategias orientadas a la competitividad. 


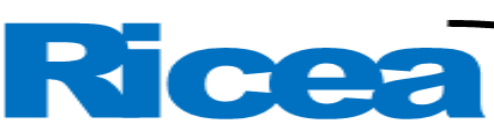

REVISTA IBEROAMERICANA DE CONTADURÍA, ECONOMIIA YADMINISTRACIÓN

Por su parte, el modelo de las 4P propuesto por Ward (2004) considera que las empresas familiares longevas poseen ciertas ventajas competitivas especiales y particulares: la política, el propósito, el proceso y el parentesco. Respecto a la primera, determina las decisiones presentes y futuras de las personas (Vallejo, 2011). Además, trae consigo una atención eficiente de conflictos y una comunicación efectiva. Vanoni y Pérez (2015) acotan que la comunicación es muy importante para decretar la gobernanza de la familia, el negocio y el patrimonio. En cuanto a la segunda, el propósito, se centra en la motivación familiar para integrar proyectos, ejercer con responsabilidad el patrimonio familiar y afrontar inteligentemente las adversidades en la empresa y en la familia. Los procesos buscan la solución de conflictos mediante reuniones, libertad de pensamientos, discusiones, entre otros aspectos, es decir, propone una comunicación constante, empática y la solución de conflictos para que el bienestar familiar no se anteponga al de la empresa o viceversa (Pasten y Huepe, 2011). Por último, el parentesco, según Espinoza y Espinoza (2012), encierra el vínculo familiar, busca la armonía y el buen clima familiar tanto dentro como fuera de la organización.

Estos dos modelos (4P y 4C) visualizan el desarrollo del recurso humano como una palanca de promoción para la competitividad en las empresas familiares. Nuevamente, el desarrollo de gestión empresarial, la planeación estratégica y el recurso humano delinean una fórmula que trae como resultado la permanencia de este tipo de empresas. Pérez, Solano, Uzcátegui y Zamora (2017) proponen que las empresas familiares deben prestar especial atención al área de la tecnología, así como a la investigación y al desarrollo de nuevos productos y servicios que satisfagan las necesidades de clientes con exigencias cada vez más elevadas y con alto poder adquisitivo. Ahora bien, las teorías de competitividad están directamente relacionadas con las acciones de empresarialidad, de tal forma que se debe discutir el término específico para las empresas familiares.

\section{Empresarialidad}

Figueroa, Figueroa, de los Ríos, Figueroa y Hernández (2010) establecen que la empresarialidad es la capacidad o competencia para generar y crear nuevas iniciativas empresariales, las cuales tienen influencia en el desarrollo territorial y económico. Arango (2011), por su parte, refiere al economista austríaco Kirzner, quien afirma que en toda acción humana está el elemento empresarial. Se trata del impulso y perspicacia para plantear fines y diseñar los medios para alcanzarlos. 


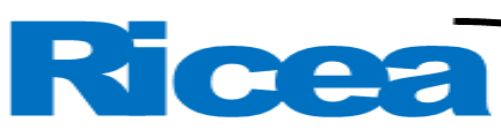

REVISTA IBEROAMERICANA DE CONTADURÍA, ECONOMÍA YADMINISTRACIÓN

$1 S S N=2007-9907$

Por otra parte, el emprendedurismo es considerado como la habilidad que se desarrolla a través de la educación. Bossio (2017) considera que la educación en emprendimiento, el fomento de la cultura emprendedora y la empresarialidad son claves para generar desarrollo empresarial y equidad. Por lo que respecta al enfoque de este trabajo, el emprendedurismo debe ser promovido en el medio rural y la educación, la cultura y la empresarialidad nunca deben de olvidarse dentro de la empresa-familia: ambas acciones traerán como resultado la perdurabilidad de las empresas rurales. Parra (2010) aclara que las microempresas rurales son todas aquellas unidades permanentes de producción de bienes y servicios en el sector rural en las que el empresario y su familia son a la vez trabajadores de la empresa.

La empresa familiar es la generalidad dentro del rubro de las mipymes en México, y más común es esta constitución empresarial en el ámbito rural. Al respecto, Belausteguigoitia (2014) enlista seis problemas profundos de este tipo de organizaciones: familiarismo (nepotismo), confusión entre empresa y familia, exceso de familiares en la empresa (rivalidad), resentimiento (conflicto), generación de prisioneros y organización poco profesional. Aun con todo, uno de los principales problemas de las empresas familiares es que carecen de un plan de sucesión, lo cual suele provocar el declive de estas organizaciones.

Beltrán, Salinas y Argüelles (2014) establecen que un plan de sucesión efectivo debe buscar en el sucesor competencias y valores empresariales, agilidad para planear y abordar con rapidez las necesidades de la empresa, capacidad de retener y desarrollar los mejores talentos y capacidad para evaluar las necesidades actuales y futuras de la empresa. Lacayo y García (2011) suman una debilidad más, a saber, la comunicación poco efectiva que suele existir en las empresas familiares, lo que redunda en problemas de tipo administrativo. De acuerdo con Alfonso Del Valle Azcué (Notimex, 2 de febrero de 2012), director de la consultora Crecimiento Sustentable, el desarrollo de habilidades de comunicación en los gerentes de las empresas familiares para escuchar y ofrecer información a sus subordinados es la clave del éxito en este tipo de empresas.

Del otro lado de la moneda, y como se ha mencionado líneas arriba, las empresas familiares también cuentan con ventajas importantes en comparación con otro tipo de organizaciones. Goyzueía (2013) enumera seis de ellas: 1) compromiso (sentido de pertenencia), 2) conocimiento (know-how), 3) flexibilidad (la familia dedica su tiempo al trabajo de su empresa), 4) planeación a largo plazo (la familia es eficiente al planificar a futuro), 5) confiabilidad y orgullo (orgullo del fundador extendido a los miembros de su 


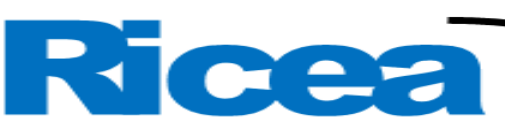

REVISTA IBEROAMERICANA DE CONTADURÍA, ECONOMIIA YADMINISTRACIÓN

ISSN $=2007-9907$

familia) y 6) cultura estable (la antigüedad de los empleados forja la cultura y los valores del desempeño). Aún más, siguiendo con Goyzueía (2013), todas estas ventajas se traducen en valores específicos de la empresa familiar: mayor grado de compromiso y dedicación; mayor grado de autofinanciación y reinversión; mejor orientación al mercado; mayor vinculación con los clientes; comportamiento más entusiasta de los trabajadores; importante afán de superación y capacidad de progreso, y flexibilidad competitiva y capacidad de ajuste. Es decir, la comunicación y la colaboración entre familiares pueden ser la diferencia entre una empresa exitosa y una fallida.

\section{Alianzas estratégicas}

La asociatividad en las mipymes busca mejorar la actividad comercial, financiera y operativa. En menor medida, se prefiere la asociación para la cooperación en aspectos administrativos y mejoras en la prestación del servicio, así lo afirman Molina et al. (2009). Bajo el mismo orden de ideas, Molina y Vasquez (2009) consideran a las alianzas estratégicas que realizan las mipymes con otras organizaciones una alternativa para obtener una ventaja competitiva, debido a que se puede lograr un fortalecimiento administrativo, una consolidación financiera y un mejoramiento en el proceso operativo. Al mismo tiempo, las alianzas apoyan la flexibilidad, el dinamismo, el instinto de supervivencia, el ambiente de confianza y el alto sentido de colaboración. Las alianzas realizadas en las mipymes auguran una alta posibilidad de éxito, así lo afirma Rodríguez (2015).

El propio Rodríguez (2015) explica que las alianzas estratégicas se practican generalmente para defenderse de las grandes compañías y así formar parte de un entorno competitivo. Elizarraráz, Molina, Quintero, Sánchez y García (2018) comentan que las alianzas estratégicas suponen un liderazgo transformacional en estas empresas. Normalmente, vienen precedidas de una comunicación asertiva y una motivación bidireccional, todo lo cual se traduce en un mejor clima laboral, satisfacción del cliente, desarrollo de producto o servicio y la creación de ventajas competitivas. Navarrete (2012) respalda esta idea de que la conformación de alianzas por parte de las mipymes es el reflejo de una comunicación efectiva que permite el acopio de información, la toma de decisiones y la ejecución de estas. Por último, Navarrete (2012) menciona que el Foro Económico Mundial [WEF, por sus siglas en inglés] (2010) afirma que en la medida en que las mipymes tengan una buena cultura organizacional la productividad mejorará, debido a la toma de decisiones acertadas, lo que les permitirá ser más competentes e innovar de forma constante. 


\section{Relación con los clientes}

En el libro coordinado por Nogales (2007) se sugiere que toda planificación racional inicie por el análisis de las necesidades futuras de la empresa y de las necesidades del cliente o consumidor. Los autores de este documento plantean que la razón de ser de una empresa reside en la existencia de clientes satisfechos (Nogales, 2007). El conocimiento de las necesidades de los clientes inicia con la atención que se ofrece al cliente. Ward (2004) menciona que una empresa debe desarrollar competencias para servir y gestionar de forma responsable el dinero de los clientes. Además, indica que un líder debe añadir nuevas dimensiones de análisis del servicio al cliente, las cuales dependerán del tipo de empresa, del tipo de producto o servicio que se ofrece, así como del entorno donde se desarrolla el negocio.

La relación con los clientes y la satisfacción de estos permite a las empresas familiares perdurar en el tiempo (de generación en generación); sin embargo, la fidelidad del cliente no solo recae en los precios de venta o en la calidad del producto. Ayup, De la Garza y Banda (2008, citados en Soto, 2013) reconocen que la imagen de marca y la cultura organizacional también impactan en la permanencia y el posicionamiento de la empresa familiar. Blanco (2009) comparte que la atención al cliente, así como tangibles de limpieza, orden, apariencia externa de las instalaciones físicas, personal y equipos, también afectan la decisión de compra de los clientes.

Ferrell y Hartline (2009) indican que la imagen de la empresa y sus productos pueden llegar al punto en el que el cliente se convierte en un verdadero seguidor satisfecho de la empresa o sus productos. No obstante, la satisfacción no suele asegurar la fidelización del cliente. El considerar que un cliente satisfecho es un cliente fiel es un error (Chiesa de Negri, 2009). La satisfacción del cliente suele depender de las garantías que se ofrecen, así como de las promociones que se brindan al comprador. Indudablemente, las mipymes del medio rural también deben considerar estos aspectos de relación con los clientes en su proceso de formalización.

\section{Recursos humanos}

Sánchez y Herrera (2016) exponen que la teoría basada en recursos y capacidades de la empresa tiene especial interés en el papel del recurso humano y las capacidades de elaboración de estrategias y determinantes principales de la rentabilidad. Las mipymes del medio rural no son ajenas a esta teoría, debido a que estas organizaciones son 


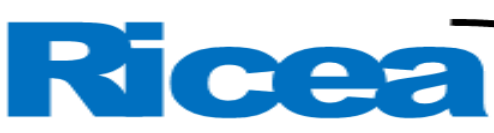

REVISTA IBEROAMERICANA DE CONTADURÍA, ECONOMÍA Y ADMINISTRACIÓN

ISSN : $2007-9907$

fundamentalmente heterogéneas en sus recursos y capacidades internas. Las dos premisas que se plasman en esta teoría son: 1) los recursos y capacidades internos proveen la dirección básica para la estrategia de la organización y 2) los recursos y capacidades son la fuente primaria de beneficios o rentabilidad para la empresa.

Ketkar y Sett (2009) corroboran que la flexibilidad en los comportamientos mejora el rendimiento empresarial en tres niveles: rendimiento del trabajador, rendimiento operativo y rendimiento financiero; es decir, las promociones laborales y las capacitaciones relacionadas con la atención al cliente permiten rendimientos financieros $\mathrm{y}$, a su vez, eleven la competitividad empresarial. Hoy en día, un factor de competitividad con el que cuentan las organizaciones es el talento humano, el cual aporta a la organización habilidades, destrezas y competencias. El recurso humano es considerado el activo más valioso de una organización (Prieto, 2013). Igualmente, los autores aquí citados concuerdan que el factor humano debidamente capacitado contribuye a que las organizaciones utilicen menos recursos para aportar el mismo nivel de negocio.

Cabe señalar que la competitividad empresarial se basa en la aplicación de nuevas estrategias empresariales, y que el principal indicador de esta es el recurso humano. Es por ello por lo que las empresas deben poner mucha atención a los procesos de contratación, capacitación y promoción del personal. Asimismo, las mipymes deben desarrollar su talento humano para el logro de sus objetivos empresariales (Solleiro y Castañón 2005; Saavedra 2012). En las empresas familiares se trabaja preponderantemente en equipo, condición que impacta en el desarrollo del trabajo, así como en las remuneraciones que reciben los integrantes del equipo. Para lograr una colaboración armónica, se requiere de una serie de estrategias, procedimientos y metodologías (Jaramillo 2012). Y en esa línea, Saavedra (2012) y Jaramillo (2012) suponen que el trabajo en equipo manifiesta un cambio organizativo en las empresas familiares, debido a que la interacción entre los miembros de la familia-empresa pueden influir en la dirección, motivación, comunicación y participación organizativa con una actitud cooperativa y no individualista. 


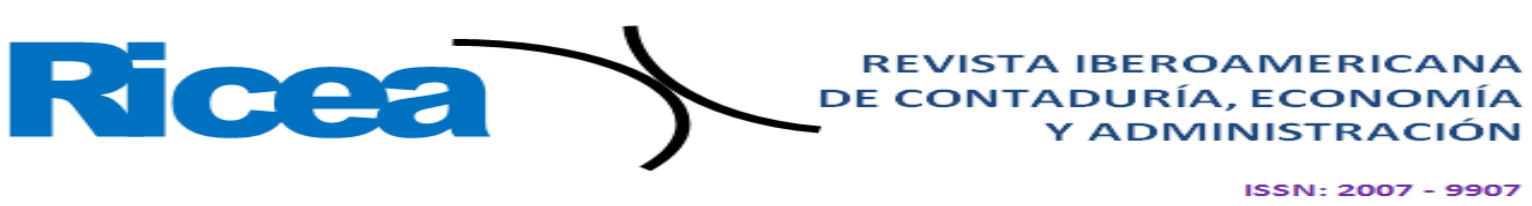

\section{Planeación estratégica}

Entre la planeación estratégica que ejecuta la pequeña y la gran empresa no hay diferencias; solo se considera que existe un nivel mayor en las decisiones sobre bienes o servicios, ubicación geográfica, estructura y designación de gerentes, entre otros. La planeación estratégica debe considerar el rumbo, directrices o políticas que guíen y faciliten las decisiones de la empresa para desenvolverse en lo interno y en lo externo. Esto determinará el fracaso o éxito de la organización (Contreras, 2013). Las mipymes, al buscar su permanencia, idean formas de comercialización. Contreras (2013) distingue que la estrategia es la determinación de metas y objetivos a largo plazo, así como la determinación de acciones a emprender y la asignación de recursos para el logro de metas. Cada uno de los autores anteriormente nombrados confirman que la esencia y naturaleza del negocio es lo que permite una planeación para el futuro.

En efecto, las mipymes del medio rural deberán fortalecer sus estrategias de mercado para hacerse más competitivas. Cerón, Alcántara y Figueroa (2010) confirman que las estrategias de mercado permiten realizar una mezcla de productos en un surtido de tamaños, colores, modelos, precios y calidad del producto ofrecido. Algunas de estas estrategias pueden ser: mezcla de productos, precio (políticas de precios), promociones, (publicidad, venta personalizada, envases o empaques y promoción en las ventas) o estrategias de distribución a través de canales o vías del dominio empresarial. Las potencialidades y habilidades del recurso humano son la fuente para que las mipymes logren una mayor interacción en el mercado.

Ahora bien, la imagen empresarial inspira confianza y profesionalismo. Las mipymes no están exentas de poder incrementar este activo. Para Castillo y Machado (2010), existen algunos beneficios sobre la imagen: fácil reconocimiento por parte de los clientes, ser rápidamente recordados, poder diferenciarse de su competidor, fungir como herramienta prospectiva de nuevos clientes y aumentar la motivación del personal actual, entre algunos otros aspectos. En este sentido, la imagen corporativa tiene como objetivo que las mipymes puedan sobresalir. La comunicación estratégica debe contribuir a formar una identidad sólida y una imagen favorable para su público (posibles socios), así lo afirma Guarneros (2014). 


\section{Metodología}

La presente investigación es de corte cuantitativo no experimental de tipo transversal, debido a que se buscó observar el comportamiento de las empresas rurales en el primer semestre del 2019. La población de estudio se conformó de empresarios (comercio y servicio) y productores de ganado (especies menores) del valle de Mexicali, Baja California, México. Más específicamente, el alcance geográfico se limitó a la delegación de Ciudad Morelos, que cuenta con ocho ejidos, cuatro colonias, cuatro poblados y 13 rancherías, con una población aproximada de 17000 habitantes. La técnica de recogida de datos fue la de bola de nieve y el instrumento para la recolección de información utilizado fue una encuesta. Dicha encuesta se compuso inicialmente de 108 ítems, divididos en ocho apartados: "Información general”, "Prospectiva personal", "Tecnologías de la comunicación", "Empresarialidad", "Recursos y actividades claves", "Conocimiento del entorno", "Relación con los clientes" y "Alianzas estratégicas".

Las variables de análisis de la presente investigación fueron: Empresarialidad (EMP), Alianzas Estratégicas (AAE), Relación con los Clientes (RC), Recursos Humanos (RH) y Planeación Estratégica (RPE). La tabla 1 muestra la operacionalización de las variables, así como los ítems evaluados que integran las variables latentes. 


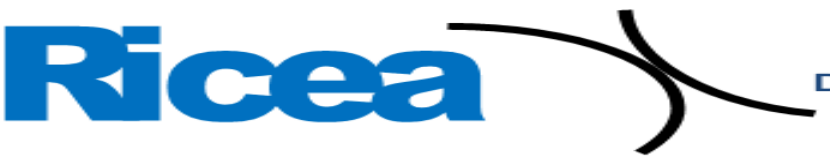

REVISTA IBEROAMERICANA DE CONTADURÍA, ECONOMÍA YADMINISTRACIÓN

Tabla 1. Operacionalización de la variable

\begin{tabular}{|c|c|c|c|c|}
\hline Variables latentes & Indicadores & $\begin{array}{l}\text { Ítems del } \\
\text { instrumento }\end{array}$ & \multicolumn{2}{|c|}{$\begin{array}{c}\text { Núm. de ítems } \\
\text { validados por } \\
\text { análisis factorial } \\
\text { (AFE) }\end{array}$} \\
\hline \multicolumn{3}{|c|}{ Total de preguntas con base en el instrumento: 35} & \multicolumn{2}{|c|}{ Permanecieron: 21} \\
\hline \multirow{3}{*}{$\begin{array}{l}\text { Empresarialidad } \\
\text { (EMP) }\end{array}$} & Plan de sucesión & \multirow[t]{3}{*}{10} & \multirow[t]{3}{*}{3} & EMP42 \\
\hline & Comunicación empresa-familia & & & EMP44 \\
\hline & Familia/trabajadores & & & EMP47 \\
\hline \multirow{4}{*}{$\begin{array}{c}\text { Alianzas } \\
\text { Estratégicas } \\
\text { (AAE) }\end{array}$} & $\begin{array}{lcl}\text { Toma } & \text { de } & \text { decisiones } \\
\text { familiares/empresa } & \end{array}$ & \multirow[t]{4}{*}{8} & \multirow[t]{4}{*}{4} & AAE73 \\
\hline & Alianzas/mejorar ingresos & & & AAE76 \\
\hline & Alianzas/mejorar servicio al cliente & & & AAE77 \\
\hline & $\begin{array}{l}\text { Alianzas/mejorar procesos } \\
\text { (competidores) }\end{array}$ & & & AAE78 \\
\hline \multirow{4}{*}{$\begin{array}{l}\text { Relación con los } \\
\text { Clientes (RC) }\end{array}$} & Capacitación en atención al cliente & \multirow[t]{4}{*}{6} & \multirow[t]{4}{*}{4} & RC69 \\
\hline & Comodidad de instalaciones/cliente & & & RC70 \\
\hline & Garantías & & & RC71 \\
\hline & Promociones & & & RC72 \\
\hline \multirow[t]{4}{*}{$\begin{array}{c}\text { Recursos } \\
\text { Humanos (RH) }\end{array}$} & $\begin{array}{lll}\text { Promociones } & \text { laborales } & \text { por } \\
\text { habilidades } & & \end{array}$ & \multirow[t]{4}{*}{5} & \multirow[t]{4}{*}{4} & RRH 87 \\
\hline & $\begin{array}{lll}\text { Promociones } & \text { laborales } & \text { por } \\
\text { productividad } & & \\
\end{array}$ & & & RRH 88 \\
\hline & Contrataciones/realizar entrevistas & & & RRH 90 \\
\hline & Capacitación & & & RRH 91 \\
\hline \multirow[t]{5}{*}{$\begin{array}{c}\text { Planeación } \\
\text { Estratégica (RPE) }\end{array}$} & $\begin{array}{lll}\text { Estrategias } & \text { de } & \text { mercado } \\
\text { (competencia) } & & \\
\end{array}$ & \multirow[t]{5}{*}{6} & \multirow[t]{5}{*}{6} & RPE102 \\
\hline & $\begin{array}{l}\text { Infraestructura/renovación de } \\
\text { equipo }\end{array}$ & & & RPE104 \\
\hline & Innovación/nuevos productos & & & RPE105 \\
\hline & Mercado/nuevos mercados & & & RPE106 \\
\hline & Imagen empresarial & & & RPE107 \\
\hline
\end{tabular}



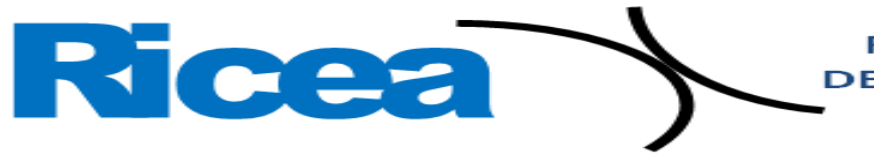

REVISTA IBEROAMERICANA DE CONTADURÍA, ECONOMÍA Y ADMINISTRACIÓN

Fuente: Elaboración propia

Para maximizar el poder explicativo del conjunto de variables, el instrumento se validó con el análisis factorial exploratorio (AFE). En consecuencia, de los 35 ítems que se utilizaron para esta investigación, tan solo permanecieron 21: la variable EMP con tres ítems, AAE con cuatro, RC con cuatro, RH con cuatro y RPE con seis ítems. Para la comprobación de las hipótesis, se utilizó el método multivariante de segunda generación denominado modelación de ecuaciones estructurales con mínimos cuadrados parciales (PLS-SEM, por sus siglas en inglés). Esta técnica cuantitativa de modelización de ecuaciones estructurales fundamentada en el análisis a partir de la varianza, como el de mínimos cuadrados perfectos (PLS), tiene como finalidad predecir y explorar las variables (Henseler, Hugona y Ash Ray, 2016). Por su parte, los SEM en las ciencias sociales permiten reconocer las relaciones causales entre constructos y con ello crear modelos del error de medida (Fornell, 1982).

El enfoque basado en varianzas PLS-SEM se utiliza en investigaciones de tipo predictivo, exploratorio y confirmatorio (Henseler et al, 2016). Este trabajo evaluó el modelo de medida y posteriormente la estructura del modelo tipo reflectivo. Rigdon (1998) indica que las ecuaciones estructurales examinan simultáneamente relaciones de interdependencia entre constructos, los cuales representan a variables, y a su vez se lleva a cabo mediciones de error. Kwong-Kay (2013) comenta que la PLS-SEM es conocida por su capacidad para manejar tamaños pequeños de muestra. Por su parte, Hoyle (1995) recomienda un tamaño de muestra de 100 a 200 para potencializar los resultados. La muestra de esta investigación consideró a 281 mipymes rurales del valle de Mexicali, por lo que se cumplió con los parámetros mencionados por los autores, con la finalidad última de obtener robustez en los resultados.

La técnica PLS-SEM permitió realizar la validez de contenido, la fiabilidad, evaluada por el alfa de Cronbach, y la fiabilidad compuesta; se corrió la validez convergente (varianza extraída media [AVE, por sus siglas en inglés]). También se constató la validez discriminante por medio del criterio de Fornell-Larcker, cargas cruzadas y el criterio Heterotrait-Monotrait Ratio (HTMT). Posteriormente, se sustentaron y comprobaron las hipótesis apoyándose en los valores de $t$ de Student, coeficiente de Path (estandarizados $ß$ ) y $p$-value. Para finalizar las pruebas estadísticas, se ejecutó la capacidad predictiva $\left(\mathrm{R}^{2}\right)$, relevancia predictiva $\left(\mathrm{f}^{2}\right)$ y el criterio de ajuste del modelo global (SRMR, por sus siglas en inglés). Estas pruebas corroboran la capacidad de predicción de los constructos, así como la relevancia entre los mismos; para apoyar a la eficiencia del ajuste global del modelo estructural. 


\section{Resultados}

El modelo de segundo orden propuesto contiene indicadores reflectivos para cada una de las actividades empresariales y la planeación estratégica. El PLS permite calcular constructos de primer y segundo orden; los primeros son reflectivos o formativos y los segundos solo reflectivos (Chin y Gopal, 1995). El modelo estructural propuesto estudia las correlaciones bivariadas entre los indicadores reflectivos resaltando la correlación entre estos (ver figura 2).

Figura 2. Modelo teórico de empresarialidad rural

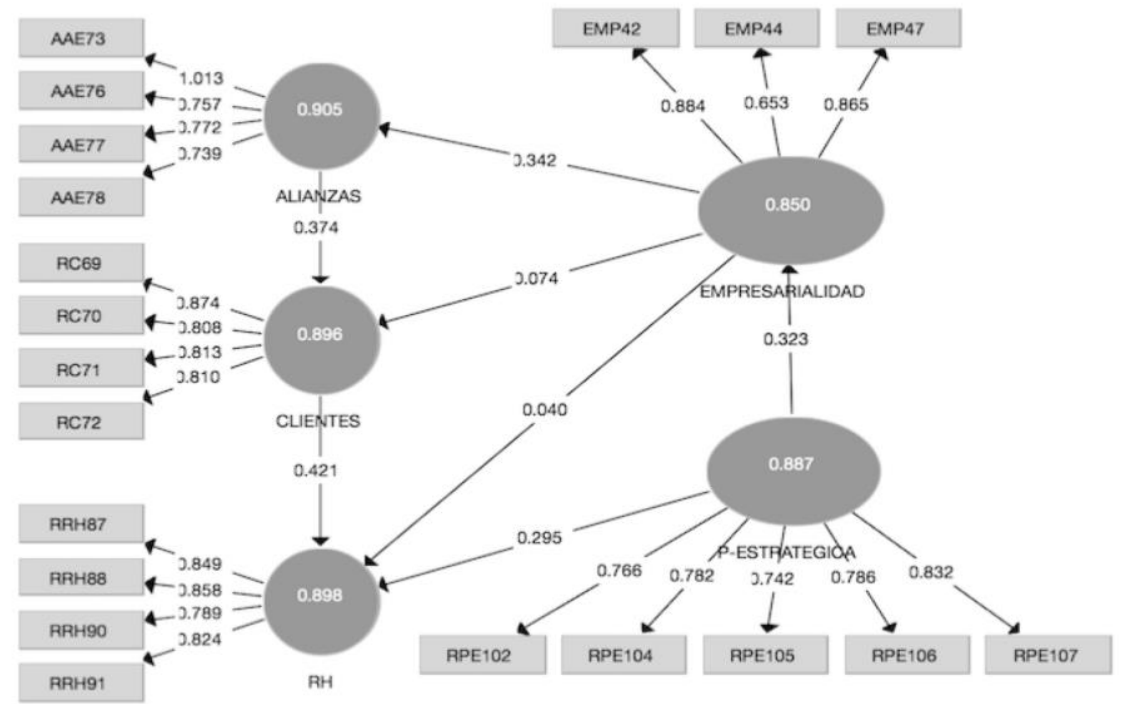

Nota: el modelo estructural presenta la relación entre la variable independiente Planeación Estratégica y su influencia en Empresarialidad, al igual que la manera en que esta ejerce influencia sobre Alianzas Estratégicas, Relación con los Clientes y Recursos Humanos. De igual manera, se presenta en este modelo la influencia que ejerce Alianzas Estratégicas sobre Relación con los Clientes y cómo actúan sobre Recursos Humanos. Por último, se muestra la influencia que ejerce Planeación Estratégica con Recursos Humanos.

Fuente: Elaboración propia

El modelo reflectivo se evaluó a través de las pruebas estadísticas de validez convergente y consistencia interna (tabla 2). La validez convergente mide la correlación que los indicadores tienen sobre un concepto, la cual debe ser alta y positiva para medir el mismo concepto (Sánchez y Jiménez, 2013). El AVE confirma la validez convergente, la cual mide la cantidad de varianza que un constructo puede extraer de sus indicadores en relación con la 


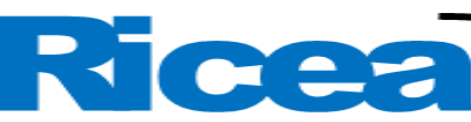

REVISTA IBEROAMERICANA DE CONTADURÍA, ECONOMÍA YADMINISTRACIÓN

ISSN : $2007-9907$

varianza relacionada con el error de medida (Fornell y Larcker, 1981). Para Ringle y Sarstedt (2011), el AVE debe ser superior a 0.50. Este modelo presenta un AVE para las variables AAE de 0.685, RC 0.683, EMP 0.653, RH 0.689 y RPE de 0.612, lo que indica que los constructos están explicados en más de $60 \%$ en todas las variables.

La consistencia interna (alfa de Cronbach y fiabilidad compuesta) de todos los indicadores evalúa la solidez de las variables manifiestas para un constructo. Para Nunnally (1978), estos indicadores deben alcanzar al menos un valor de 0.7. Los resultados obtenidos en los modelos de medida muestran una consistencia interna aceptable: AAE (FC $=0.895 ; \alpha$ $=0.905), \mathrm{RC}(\mathrm{FC}=0.896 ; \alpha=0.896), \operatorname{EMP}(\mathrm{FC}=0.847 ; \alpha=0.850), \operatorname{RPE}(\mathrm{FC}=0.887 ; \alpha=$ $0.887)$ y para $\mathrm{RH}(\mathrm{FC}=0.891 ; \alpha=0.898)$. 


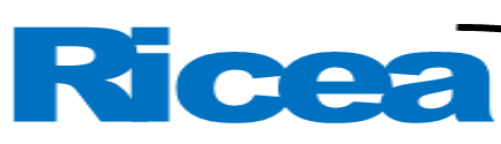

REVISTA IBEROAMERICANA DE CONTADURÍA, ECONOMÍA YADMINISTRACIÓN

Tabla 2. Validez convergente y consistencia interna

\begin{tabular}{|c|c|c|c|c|c|c|}
\hline \multicolumn{4}{|c|}{ Valores } & \multirow{2}{*}{$\begin{array}{c}\text { Validez } \\
\text { Convergent } \\
\mathrm{e} \\
\mathrm{AVE} \\
>0.50\end{array}$} & \multicolumn{2}{|c|}{ Consistencia interna } \\
\hline $\begin{array}{l}\text { Variable } \\
\text { latente }\end{array}$ & $\begin{array}{l}\text { Ítem o } \\
\text { indicador }\end{array}$ & $\begin{array}{c}\text { Cargas } \\
\text { factoriale } \\
\mathrm{s} \\
>.0 .60\end{array}$ & $\begin{array}{c}\text { Valores t } \\
>1.96\end{array}$ & & $\begin{array}{l}\text { Fiabilidad } \\
\text { compuesta } \\
\text { (FC) } \\
0.70-0.90\end{array}$ & $\begin{array}{c}\text { Alfa de } \\
\text { Cronbach } \\
0.70-0.90 \\
(\alpha)\end{array}$ \\
\hline \multirow{4}{*}{$\begin{array}{c}\text { Alianzas } \\
\text { Estratégicas } \\
\text { (AAE) }\end{array}$} & AAE73 & 1.013 & 26.353 & 0.685 & 0.895 & 0.905 \\
\hline & AAE76 & 0.757 & 37.650 & & & \\
\hline & AAE77 & 0.772 & 54.254 & & & \\
\hline & AAE78 & 0.739 & 49.907 & & & \\
\hline \multirow{4}{*}{$\begin{array}{c}\text { Relación con } \\
\text { los Clientes } \\
\text { (RC) }\end{array}$} & RC69 & 0.874 & 43.757 & 0.683 & 0.896 & 0.896 \\
\hline & $\mathrm{RC70}$ & 0.808 & 39.677 & & & \\
\hline & RC71 & 0.813 & 49.740 & & & \\
\hline & RC72 & 0.810 & 33.517 & & & \\
\hline \multirow{3}{*}{$\begin{array}{c}\text { Empresarialida } \\
\text { d (EMP) }\end{array}$} & EMP42 & 0.884 & 32.112 & 0.653 & 0.847 & 0.850 \\
\hline & EMP44 & 0.653 & 27.777 & & & \\
\hline & EMP47 & 0.865 & 42.247 & & & \\
\hline \multirow{5}{*}{$\begin{array}{c}\text { Planeación } \\
\text { Estratégica } \\
\text { (RPE) }\end{array}$} & RPE102 & 0.766 & 24.420 & 0.612 & 0.887 & 0.887 \\
\hline & RPE104 & 0.782 & 30.575 & & & \\
\hline & RPE105 & 0.742 & 36.331 & & & \\
\hline & RPE106 & 0.786 & 33.997 & & & \\
\hline & RPE107 & 0.832 & 46.318 & & & \\
\hline \multirow{4}{*}{$\begin{array}{c}\text { Recursos } \\
\text { Humanos (RH) }\end{array}$} & RRH87 & 0.849 & 49.748 & 0.689 & 0.891 & 0.898 \\
\hline & RRH88 & 0.858 & 73.354 & & & \\
\hline & RRH90 & 0.789 & 36.139 & & & \\
\hline & RRH91 & 0.824 & 35.303 & & & \\
\hline
\end{tabular}

Fuente: Elaboración propia

El análisis de las cargas factoriales explica su variable latente correspondiente. Carmines y Zeller (1979) consideran un valor de 0.707 como objetivo de medida. Pere y Anguiano (2010) consideran que un valor de 0.60 es aceptable. Este modelo presenta en todas 


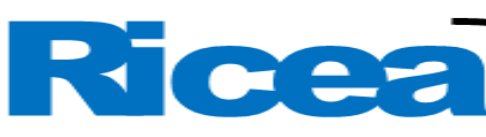

REVISTA IBEROAMERICANA DE CONTADURÍA, ECONOMÍA YADMINISTRACIÓN

ISSN $=2007-9907$

sus variables latentes indicadores superiores a 0.739. El ítem EMP44 obtuvo un valor de 0.653, el cual permanece en la evaluación del constructo debido a la importancia que conlleva la comunicación empresa-familia. Para determinar la robustez del modelo de medida y la significancia en la relación entre las variables, se aplicó el procedimiento de bootstrapping (5000 submuestras). El estadístico $t$ de Student alcanzó valores superiores a 1.96 en todos sus indicadores; obtuvo valores desde 24.420 hasta 73.354 , lo que indica que el modelo es significativo (tabla 2).

Tabla 3. Validez discriminante (criterio de Fornell-Larcker)

\begin{tabular}{|c|c|c|c|c|c|}
\hline $\begin{array}{l}\text { Constructos } \\
\text { latentes }\end{array}$ & $\begin{array}{c}\text { Alianzas } \\
\text { Estratégicas }\end{array}$ & $\begin{array}{l}\text { Relación con } \\
\text { los Clientes }\end{array}$ & $\begin{array}{c}\text { Empresarialid } \\
\text { ad }\end{array}$ & $\begin{array}{c}\text { Planeació } \\
\mathrm{n} \\
\text { Estratégic } \\
\mathrm{a}\end{array}$ & $\begin{array}{c}\text { Recurso } \\
\text { s } \\
\text { Human } \\
\text { os }\end{array}$ \\
\hline $\begin{array}{l}\text { Alianzas } \\
\text { Estratégicas (AAE) }\end{array}$ & 0.828 & & & & \\
\hline $\begin{array}{l}\text { Relación con los } \\
\text { Clientes (RC) }\end{array}$ & 0.399 & 0.826 & & & \\
\hline $\begin{array}{l}\text { Empresarialidad } \\
(\mathrm{EMP})\end{array}$ & 0.342 & 0.202 & 0.808 & & \\
\hline $\begin{array}{l}\text { Planeación } \\
\text { Estratégica (RPE) }\end{array}$ & 0.388 & 0.791 & 0.323 & 0.782 & \\
\hline $\begin{array}{l}\text { Recursos Humanos } \\
\text { (RH) }\end{array}$ & 0.325 & 0.663 & 0.221 & 0.641 & 0.830 \\
\hline
\end{tabular}

Fuente: Elaboración propia

La validez discriminante es un criterio de evaluación complementario a la validez convergente, la cual se refiere a que dos variables latentes deben exhibir conceptualmente sus diferencias, es decir, una escala solo debe medir las características del concepto que pretende representar y no el de otro constructo (Sánchez y Jiménez, 2013). La tabla 3 presenta de forma diagonal la raíz cuadrada del AVE de cada variable latente. Como requisito de cumplimiento de esta medida, los valores en diagonal deben de ser mayores que la correlación entre un constructo y el resto de los constructos del modelo (Chin, 2010). Es decir: este modelo cumple con el factor de medida. 


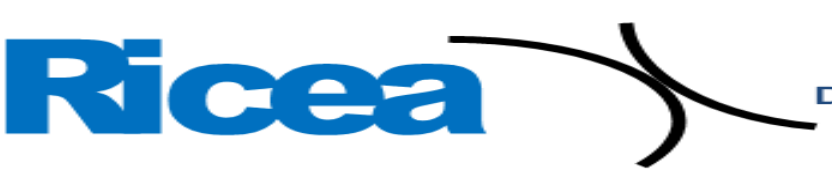

REVISTA IBEROAMERICANA DE CONTADURIA, ECONOMÍA YADMINISTRACIÓN

Un análisis adicional en la validez discriminante lo son las cargas factoriales cruzadas, las cuales deben presentar mayor valor con su propia variable que con otra que integre el modelo (Barclay, Higgins y Thompson, 1995). La tabla 4 muestra que el conjunto de indicadores de una variable ha cargado más sobre su variable que sobre los indicadores de los otros constructos.

Tabla 4. Cargas factoriales cruzadas

\begin{tabular}{|l|r|r|r|r|r|}
\hline & $\begin{array}{c}\text { Alianzas } \\
\text { Estratégicas }\end{array}$ & $\begin{array}{c}\text { Relación con } \\
\text { los Clientes }\end{array}$ & Empresarialidad & $\begin{array}{c}\text { Planeación } \\
\text { Estratégica }\end{array}$ & $\begin{array}{c}\text { Recursos } \\
\text { Humanos }\end{array}$ \\
\hline AAE73 & 0.966 & 0.344 & 0.436 & 0.333 & 0.302 \\
\hline AAE76 & 0.794 & 0.331 & 0.204 & 0.336 & 0.271 \\
\hline AAE77 & 0.794 & 0.337 & 0.223 & 0.324 & 0.258 \\
\hline AAE78 & 0.752 & 0.316 & 0.226 & 0.299 & 0.243 \\
\hline EMP42 & 0.286 & 0.191 & 0.852 & 0.304 & 0.133 \\
\hline EMP44 & 0.250 & 0.120 & 0.651 & 0.182 & 0.148 \\
\hline EMP47 & 0.283 & 0.171 & 0.900 & 0.283 & 0.251 \\
\hline RC69 & 0.377 & 0.888 & 0.197 & 0.641 & 0.642 \\
\hline RC70 & 0.272 & 0.813 & 0.181 & 0.683 & 0.518 \\
\hline RC71 & 0.280 & 0.813 & 0.117 & 0.658 & 0.561 \\
\hline RC72 & 0.387 & 0.790 & 0.169 & 0.637 & 0.463 \\
\hline RPE102 & 0.340 & 0.608 & 0.209 & 0.766 & 0.482 \\
\hline RPE104 & 0.274 & 0.616 & 0.289 & 0.782 & 0.505 \\
\hline RPE105 & 0.259 & 0.602 & 0.298 & 0.742 & 0.447 \\
\hline RPE106 & 0.353 & 0.603 & 0.264 & 0.786 & 0.491 \\
\hline RPE107 & 0.292 & 0.662 & 0.206 & 0.831 & 0.576 \\
\hline RRH87 & 0.308 & 0.564 & 0.274 & 0.498 & 0.848 \\
\hline RRH88 & 0.265 & 0.582 & 0.246 & 0.524 & 0.858 \\
\hline RRH90 & 0.224 & 0.511 & 0.122 & 0.554 & 0.789 \\
\hline RRH91 & 0.278 & 0.544 & 0.089 & 0.558 & 0.824 \\
\hline
\end{tabular}

Fuente: Elaboración propia 


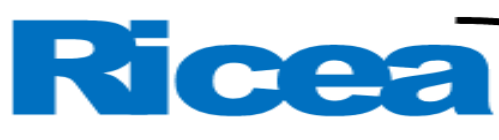

REVISTA IBEROAMERICANA DE CONTADURÍA, ECONOMÍA YADMINISTRACIÓN

ISSN $=2007-9907$

Otra medida para la evaluación de la validez discriminante entre las variables latentes es el criterio HTMT, el cual debe contar con un valor por debajo de uno, según Gold, Malhotra y Segars (2001). De igual manera, es considerado como un valor conservador el encontrarse por debajo de 0.90 (Henseler, Ringle y Sarstedt, 2015). La tabla 5 muestra que existe validez discriminante entre los constructos que conforman el modelo estructural, debido a que sus valores se encuentran por debajo del valor umbral establecido por los autores mencionados.

Tabla 5. Validez discriminante por la prueba HTMT

\begin{tabular}{|l|l|l|l|l|}
\hline \multicolumn{1}{|c|}{ Constructos } & \multicolumn{1}{|c|}{$\begin{array}{c}\text { Alianzas } \\
\text { Estratégicas }\end{array}$} & $\begin{array}{l}\text { Relación con } \\
\text { los Clientes }\end{array}$ & Empresarialidad & $\begin{array}{l}\text { Planeación } \\
\text { Estratégica }\end{array}$ \\
\hline $\begin{array}{l}\text { Relación con los } \\
\text { Clientes (RC) }\end{array}$ & 0.487 & & & \\
\hline $\begin{array}{l}\text { Empresarialidad } \\
\text { (EMP) }\end{array}$ & 0.435 & 0.323 & 0.452 & \\
\hline $\begin{array}{l}\text { Planeación } \\
\text { Estratégica (RPE) }\end{array}$ & 0.480 & 0.849 & 0.339 & 0.723 \\
\hline $\begin{array}{l}\text { Recursos } \\
\text { Humanos (RH) }\end{array}$ & 0.408 & 0.740 & & \\
\hline
\end{tabular}

Fuente: Elaboración propia

Para la comprobación de las hipótesis se realizaron tres pruebas estadísticas. En primer lugar, se estimó el coeficiente de regresión estandarizado Path, el cual mide el grado de variación producida en la variable dependiente por cada una de las variables independientes (Wright, 1923). En segundo lugar, se analizó la significancia a través de la $t$ de Student, considerada como una técnica no paramétrica que evalúa la precisión de las estimaciones. Por último, se determinó el $p$-value, este es considerado como un método que evalúa la significación en la aceptación o rechazo de las hipótesis. Este modelo presenta la relación de siete hipótesis, donde la empresarialidad se relaciona con alianzas estratégicas, relación con sus clientes, recursos humanos y planeación estratégica.

La tabla 6 muestra los resultados de las hipótesis. Las variables exógenas ejercen un efecto positivo sobre las variables endógenas. Los valores obtenidos fueron los siguientes: 


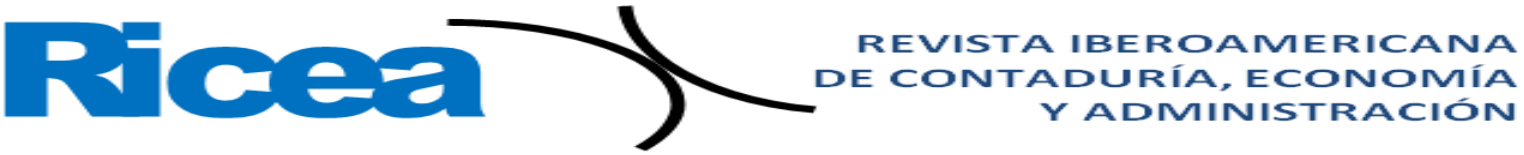

- $\quad \mathrm{H}_{1}: \mathrm{RPE} \rightarrow$ EMP obtuvo valores de $\beta=0.283, t=4.873, p=0.000$;

- $\quad \mathrm{H}_{2}: \mathrm{EMP} \rightarrow$ AAE logró valores de $\beta=0.306, t=5.736, p=0.000$;

- $\quad \mathrm{H}_{3}: \mathrm{EMP} \rightarrow \mathrm{RC}$ generó valores de $\beta=0.074, t=1.155, p=0.235$;

- $\quad \mathrm{H}_{4} \mathrm{EMP} \rightarrow \mathrm{RH}$ reflejó valores de $\beta=0.045, t=0.766, p=0.403$

- $\quad \mathrm{H}_{5}: \mathrm{AAE} \rightarrow \mathrm{RC}$ arrojó valores de $\beta=0.341, t=6.797, p=0.000$;

- $\quad \mathrm{H}_{6}: \mathrm{RC} \rightarrow \mathrm{RH}$ resultó con valores de $\beta=0.389, t=5.162, p=0.000, \mathrm{y}$

- $\quad \mathrm{H}_{7}: \mathrm{RPE} \rightarrow \mathrm{RH}$ mostró valores de $\beta=0.287, t=3.752, p=0.000$.

Los valores obtenidos muestran que las hipótesis aceptadas son $\mathrm{H}_{1}, \mathrm{H}_{2}, \mathrm{H}_{5}, \mathrm{H}_{6}$ y $\mathrm{H}_{7}$ y las hipótesis rechazadas lo fueron $\mathrm{H}_{3} \mathrm{y} \mathrm{H}_{4}$.

Tabla 6. Coeficientes de Path (coeficientes de regresión estandarizados)

\begin{tabular}{|l|c|c|c|c|}
\hline \multicolumn{1}{|c|}{ Relación de hipótesis } & $\begin{array}{c}\text { Coeficientes de } \\
\text { Path } \\
\text { (estandarizados } 8) \\
\text { rango }+1 \mathrm{a}-1\end{array}$ & $\begin{array}{c}\text { Estadístico de } t \\
\text { Student } \\
\text { (boostrapping) }\end{array}$ & Valor $p$ & $\begin{array}{c}\text { Aceptada/R } \\
\text { echazada }\end{array}$ \\
\hline $\mathrm{H}_{1}:$ P. Estratégica $\rightarrow$ Emp & 0.283 & 4.873 & 0.000 & Aceptada \\
\hline $\mathrm{H}_{2}:$ Emp $\rightarrow$ Alianzas & 0.306 & 5.736 & 0.000 & Aceptada \\
\hline $\mathrm{H}_{3}:$ Emp $\rightarrow$ R. Clientes & 0.074 & 1.155 & 0.235 & Rechazada \\
\hline $\mathrm{H}_{4}:$ Emp $\rightarrow$ R.H & 0.045 & 0.766 & 0.403 & Rechazada \\
\hline $\begin{array}{l}\mathrm{H}_{5}: \text { Alianzas Estratégicas } \rightarrow \text { R. } \\
\text { Clientes }\end{array}$ & 0.341 & 6.797 & 0.000 & Aceptada \\
\hline $\mathrm{H}_{6}:$ R. Clientes $\rightarrow$ R. Humanos & 0.389 & 5.162 & 0.000 & Aceptada \\
\hline $\begin{array}{l}\mathrm{H}_{7}: \text { Planeación Estratégica } \rightarrow \mathrm{R} . \\
\text { Humanos }\end{array}$ & 0.287 & 3.752 & 0.000 & Aceptada \\
\hline
\end{tabular}

Fuente: Elaboración propia del autor.

Aunado a la comprobación de las hipótesis del modelo teórico de empresarialidad rural, se realizaron las pruebas predictivas al modelo estructural para determinar los valores de $\mathrm{R}^{2}, \mathrm{f}^{2}$ y SRMR. Según Chin (1998), los valores de $\mathrm{R}^{2}$ deben ser de 0.67, 0.33 y 0.10 (sustancial, moderada y débil). La prueba de $\mathrm{f}^{2}$ evalúa si el constructo omitido tiene un impacto sustantivo en los constructos endógenos (Martínez y Fierro, 2018). Para Cohen (1998), el parámetro de $\mathrm{f}^{2}$ es $0.02,0.15$ y 0.35 (pequeño, mediano y grande). $\mathrm{H}_{1}$ obtuvo $\mathrm{R}^{2}$ de 0.000 y un $\mathrm{f}^{2}$ de $0.057 ; \mathrm{H}_{2}$ arrojó un $\mathrm{R}^{2}$ de 0.111 y un $\mathrm{f}^{2}$ de 0.000 ; en $\mathrm{H}_{3}$ se generó un $\mathrm{R}^{2}$ de 


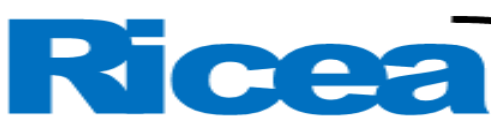

REVISTA IBEROAMERICANA DE CONTADURÍA, ECONOMÍA YADMINISTRACIÓN

ISSN $=2007-9907$

0.158 y un $\mathrm{f}^{2} 0.127 ; \mathrm{H}_{4}$ fue un $\mathrm{R}^{2}$ de 0.472 y un $\mathrm{f}^{2}$ de 0.00 . Por último, se realizó el ajuste del modelo global (SRMR) propuesto como indicador de la bondad del ajuste en PLS por Lohmöller (1989). Un valor inferior a 0.05 para Byrne (2008) indica un ajuste aceptable. El modelo analizado obtuvo bajo la prueba SRMR un valor de 0.045, lo que indica que el modelo se encuentra en un rango aceptable (ver tabla 7).

Tabla 7. Capacidad predictiva $\left(\mathrm{R}^{2}\right)$, relevancia predictiva $\left(\mathrm{f}^{2}\right)$ y el SRMR

\begin{tabular}{|l|c|c|c|}
\cline { 1 - 2 } \multicolumn{1}{|c|}{ Variables latentes (constructos) } & $\mathrm{R}^{2}$ & $\mathrm{f}^{2}$ & SRMR \\
\cline { 1 - 3 } $\mathrm{H}_{1}:$ P. Estratégica $\rightarrow$ Emp & 0.000 & 0.057 & \multirow{2}{*}{0.045} \\
\cline { 1 - 2 } $\mathrm{H}_{2}:$ Emp $\rightarrow$ Alianzas & 0.111 & 0.000 & \\
\cline { 1 - 2 } $\mathrm{H}_{3}: \mathrm{Emp} \rightarrow$ R. Clientes & 0.158 & 0.127 & \\
\cline { 1 - 3 } $\mathrm{H}_{4}: \mathrm{Emp} \rightarrow$ R.H & 0.472 & 0.000 & \\
\hline
\end{tabular}

Fuente: Elaboración propia

\section{Discusión}

Este trabajo ha determinado que la planeación estratégica sí influye en el desarrollo de la empresarialidad en las mipymes del medio rural. Sin embargo, existen estudios previos que mencionan que tan solo de $20 \%$ a $30 \%$ de estas empresas aplican la planeación estratégica, y que de estas, tan solo $73 \%$ la ejecutan con objetivos plenamente definidos (Valenzuela, López y Moreno, 2015). Esto significa que, a pesar de aplicar una planeación estratégica débilmente estructurada, las empresas del medio rural sí logran promover una empresarialidad efectiva que influya de forma positiva en las áreas de alianzas estratégicas, relación con los clientes y recursos humanos.

El valle de Mexicali cuenta con un amplio territorio donde se realizan diversas actividades comerciales y de servicios. Para este estudio fue necesario concretar uno de los poblados con mayor concentración de actividad económica; será necesario estudiar aquellas zonas rurales que presenten igual o mayor movimiento económico, esto con el propósito de lograr obtener un parámetro de comparación que otorgue una visión global del comportamiento de la empresarialidad en las mipymes de esta región. En suma, este trabajo ha detectado que la planeación estratégica es un indicador de desarrollo para las empresas familiares y que además la acción de planear promueve su empresarialidad. 


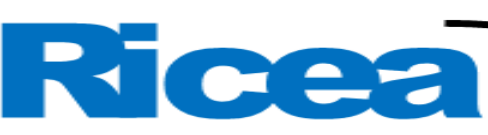

REVISTA IBEROAMERICANA DE CONTADURÍA, ECONOMÍA YADMINISTRACIÓN

\section{Conclusiones}

El modelo de competitividad de las mipymes presentado por el IFCT (2010) es aplicable también a las mipymes del medio rural. En esta investigación se analizaron los efectos que la planeación estratégica realiza sobre la empresarialidad de las mipymes rurales y cómo la empresarialidad impacta en las acciones empresariales de alianzas estratégicas, relación con los clientes y recursos humanos; adicionalmente, se analizó la relación que estas acciones ejercen entre sí.

Los resultados arrojan que existe una estrecha relación entre la planeación estratégica y la empresarialidad cuando las mipymes rurales implementan estrategias de mercado bajo la vigilancia de la competencia, en la introducción de nuevos productos y renovación de infraestructura, así como en el mejoramiento de la imagen corporativa. Una vez fortalecida la empresarialidad rural a través de la planeación estratégica, esta ejerce una influencia positiva en las alianzas estratégicas, en relación con la toma de decisiones, implementación de procesos, mejora de sus ingresos y atención al cliente.

Sin embargo, la empresarialidad ejerce una influencia menor en la relación con los clientes y recursos humanos, lo cual se atribuye a que estas actividades son consideradas de carácter interno. Por otra parte, al analizar las variables entre sí, se obtuvo que existe una influencia positiva entre Alianzas Estratégicas y Relación con los Clientes, Relación con los Clientes y Recursos Humanos, así como Planeación Estratégica y Recursos Humanos. Es decir, el modelo teórico de empresarialidad rural propuesto en esta investigación sí ejerce influencia sobre la competitividad de las mipymes.

\section{Futuras líneas de Investigación}

Los resultados obtenidos confirman que a pesar de haber rechazado la hipótesis de empresarialidad con recursos humanos, el último análisis realizado propone que recursos humanos es una actividad que impacta directamente en la competitividad, por lo tanto, se recomiendan futuras investigaciones que analicen el impacto que ejerce el recurso humano sobre el posicionamiento de las mipymes del medio rural. 


\section{Referencias}

Arango, J. (2011). Identificación de los factores que tienen mayor relevancia en la creación de una nueva empresa en la ciudad de Medellín, desde la perspectiva del emprendedor empresarial. Caso: Parque del Emprendimiento. (Tesis de maestría). Universidad de Medellín, Medellín. Recuperado de https://core.ac.uk/download/pdf/51194415.pdf.

Barclay, D., Higgins, C. and Thompson, R. (1995). The Partial Least Squares (PLS) Approach Modelling: Personal Computer Adoption and Use as Illustration. Technology Studies, 2(2), 285-309.

Belausteguigoitia, I. (2014). La empresa familiar: problemas y soluciones. Recuperado de http://cedef.itam.mx/sites/default/files/u489/laempresafamilliarproblemasysolucione s.pdf.

Beltrán, R., Selem, M. A. y Argüelles, M. A. (2014). Implementando el plan de sucesión en la empresa familiar. Ponencia presentada en el XIX Congreso Internacional de Contaduría, Administración e Informática. Ciudad de México, del 8 al 10 de octubre de 2014. http://congreso.investiga.fca.unam.mx/docs/xix/docs/1.13.pdf

Blanco, J. (2009). Medición de la satisfacción del cliente del Restaurante Museo Taurino, y formulación de estrategias de servicio para la creación de valor. (Tesis de doctorado). Pontificia Universidad Javeriana.

Bossio, C. (2017). El Emprendimiento social como una alternativa para la superación de la pobreza en Cartagena de Indias, 2005-2015. (Tesis de doctorado). Fundación Universitaria Los Libertadores, Cartagena de Indias.

Byrne, B. (2008). Structural equation modeling with EQS: basic concept, application, and Programming. Psychology Press.

Carmines, E. and Zeller, R. (1979). Reliability and Validity Assessment. Beverly, Estados Unidos: Sage.

Cerón, A., Alcántara, R. y Figueroa, J. (2010). La mercadotecnia: una estrategia de competitividad. Ponencia presentada en el V Encuentro Estatal de Investigación en Ciencias Económico Administrativas. Pachuca. Recuperado de https://www.uaeh.edu.mx/investigacion/productos/1669/.

Chiavenato, I. (2015). Administración, proceso administrativo.

Chiesa de Negri, C. (2009). CRM: Las cinco pirámides del marketing relacional. Deusto. 
Chin, W. (1998). Issues and Opinion on Structural Equation Modeling. MIS Quarterly, 22(1).

Chin, W. (2010). How to Write Up and Report PLS Analyses. In Esposito, V., Chin, W., Henseler, J. and Wang, H. (eds.), Handbook of Partial Least Squares. Berlin, Germany: Springer.

Chin, W. and Gopal, A. (1995). Adoption intention in GSS: relative importance of beliefs. IGMIS Database, 26(2-3), 42-64. Retrieved from https://doi.org/10.1145/217278.217285.

Cohen, J. (1998). Statically Power Analysis for the Behavioral Science. Ediciones Laurence Erlbaum Associates.

Contreras, E. (2013). El concepto de estrategia como fundamento de la planeación estratégica. Pensamiento y Gestión, (35), 152-181. Recuperado de https://www.redalyc.org/pdf/646/64629832007.pdf.

Castillo, J. R., y Machado, C. A. (2010). El fortalecimiento de la imagen empresarial a través de la gestión del comportamiento corporativo socialmente responsable. Contribuciones a la Economía, (2010-05)

Elizarraráz, G., Molina, H., Quintero, M., Sánchez, R. y García, C. (2018). Discursos en torno a la lucidez organizacional en las alianzas estratégicas y las redes de conocimiento entre mipymes caficultoras del centro de México. Margen, (88). Recuperado de http://www.margen.org/suscri/margen88/guarneros_88.pdf.

Espinoza, T. and Espinoza, N. (2012). Family business performance: evidence from México. Cuadernos de Administración, 25(44), 39-61.

Esser, K., Hillebrand, W., Messner, D. y Meyer, J. (1996). Systemic competitiveness: a new challenge for firms and for government. Cepal Review, (59), 39-53

Ferrell, O.C. y Hartline, M. D. (2009). Estrategia de marketing. Ediciones, Thomson.

Figueroa, B., Figueroa, K., de los Ríos, I., Figueroa, B. y Hernández, F. (2010). La empresarialidad en prestadores de servicios profesionales agropecuarios del estado de Campeche, México. Ra Ximha. 6(3), 355-364.

Fornell, C. (1982). A Second Generation of Multivariate Analysis. New York, United States: Praeger Publishers. 1-21.

Fornell, C. and Lacker, D. F. (1981). Evaluating structural equation model with unobservable variables and measurement error. Journal of Marketing Research, 18(1), 39-50.

Mungaray, A. (coord.) (2009). Programa Sectorial de Desarrollo Económico. Eje 4 Economía competitiva. 2009-2013. México, Baja California: Gobierno del Estado de 
http://sei.copladebc.gob.mx/programas_sectoriales/Sectorial_Economia.pdf.

Garcia S. (julio-diciembre 2012). Una propuesta para la determinación de la competitividad en la Pyme Latinoamericana. Pensamiento y Gestión. (33), 93-124.

Gold, A., Malhotra, A. and Segars, A. (2001). Knowledge Management: An Organizational Capabilities Perspective. Journal of Management Information Systems, 18(1), 185214.

Goyzueía, S. (2013). Modelo de gestión para las empresas familiares con perspectivas de crecimiento y sostenibilidad. Perspectivas, 16(31), 87-132.

Guarneros, I. (2014). Más competitivas que pequeñas. Imagen corporativa a la medida de su empresa. México: Grupo Editorial Patria.

Hair, J. F., Ringle, C. M. and Sarstedt, M. (2011). PLS-SEM: Indeed a Silver Bullet. Journal of Marketing Theory and Practice, 19(2), 139-151.

Henseler, J., Hugona, G. and Ash Ray, P. (2016). Using PLS path modeling in new technology research: updated guidelines. Industrial Management \& Data Systems, $116(1), 2-20$.

Henseler, J., Ringle, C. M. and Sarstedt, M. (2015). A new criterion for assessing discriminant validity in variance-based structural equation modeling. Journal of the Academic of Marketing Science, 43(1), 115-135. Retrieved from https://doi.org/10.1007/s11747-014-0403-8.

Hoyle, R. (1995). Structural Equation Modeling. Thousand Oaks, Estados Unidos: Sage.

Instituto para el Fomento a la Calidad Total [IFCT]. (2010). Modelo nacional para las mipymes competitivas. Un enfoque al diseño de un modelo de negocio innovador. Ciudad de México, México: Instituto para el Fomento a la Calidad Total. Recuperado de http://ibccmx.org/attachments/014_MNC\%20Micro\%20y\%20Peque\%C3\%B1as \%20Empresas\%202012.pdf.

Jaramillo, R. (2012). Trabajo en equipo. (Manual de trabajo). México: Subsecretaría de Administración $\quad$ y $\quad$ Finanzas. Recuperado de http://dgrh.salud.gob.mx/Formatos/MANUAL-DE-TRABAJO-EN-EQUIPO2012.pdf.

Ketkar, S. y Sett, P.K., (2009). HR flexibility and firm performance: Analysis of a multilevel causal model. International Journal of Human Resource Management. 20(5), 1009-1038. 


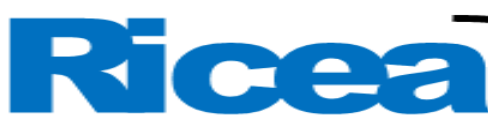

REVISTA IBEROAMERICANA DE CONTADURÍA, ECONOMÍA YADMINISTRACIÓN

ISSN $=2007-9907$

Kwong-Kay, K. (2013). Partial Least Squares Structural Equation Modeling (PLS-SEM). Techniques Using SmartPLS. Marketing Bulletin, 24, 1-32

Lacayo, M. y García, S. (2011). Principales problemas que impiden la permanencia y crecimiento de las pequeñas y medianas empresas mexicanas. Ponencia presentada en el I Encuentro Internacional AECA en América Latina. Ciudad de México, 14 y 15 de febrero de 2011. Recuperado de http://www.aeca1.org/pub/on_line/comunicaciones_aal2011/cd/62c.pdf.

Lohmöller, J. B. (1989). Latent Variable Path Modeling with partial Least Squares. Heidelberg: Physica-Verlag.

Martínez, A. y Fierro, M., (enero-junio 2018). Aplicación de la técnica PLS-SEM en la gestión del conocimiento: un enfoque técnico práctico. Revista Iberoamericana para la Investigación y Desarrollo Educativo. (8), 16. DOI: 10.23913/ride.v8i16.336

Miller, D. y Breton, I. (2006). Gestionar a largo plazo. La ventaja competitiva de las mayores empresas familiares. Bilbao, España: Ediciones Deusto.

Molina, R. y Vázquez, G. (2009). Redes de alianzas estratégicas, una opción para las micro, pequeñas y medianas empresas. Competitividad, 3(1). Recuperado de https://riico.net/index.php/riico/article/view/879.

Molina, C., Vergara, J., Oyola P., Paternina J., Herrera, G. y Sáenz, J. (2009). Las pymes de la industria manufacturera en la ciudad de Cartagena. Cartagena, Colombia: Cámara de Comercio Cartagena.

Navarrete, F. (2012). Las micro, pequeñas y medianas empresas de la Zona Metropolitana de Guadalajara: una perspectiva hacia la gestión de su proceso de toma de decisiones. Revista Electrónica Nova Scientia, 5(10), 210-236.

Nogales, F. (coord.) (2007). La empresa familiar y los nuevos retos de gestión. Fundación EOI. Recuperado de http://media.eoi.es/nw/Multimedia/PublicacionesEOI/2007_Libro_19.pdf.

Notimex. (2 de febrero de 2012). Empresas abusivas angustian al empleado. Expansión. Recuperado de https://expansion.mx/mi-carrera/2012/02/02/combate-la-angustia-entu-trabajo.

Nunnally, J. C., (1978). Psychometric theory . Ediciones McGraw-Hill.

Parra, E. (2010). Estrategias de desarrollo de las microempresas rurales. Colombia: Consejo Nacional de Planeación. 
Pasten, D. y Huepe, P. (2011). Determinantes del éxito en procesos de profesionalización en empresas familiares de tamaño mediano en Chile. (Proyecto de tesis). Universidad Católica de la Santísima Concepción, Concepción.

Pere, F. y Anguiano, C. (2010). El análisis factorial como técnica de investigación en psicología. Papeles del Psicólogo, 31(1), 18-33. Recuperado de https://www.redalyc.org/pdf/778/77812441003.pdf.

Pérez, M. J., Solano, J., Uzcátegui, C. y Zamora, I. P. (2017). Competitividad en empresas familiares. Ponencia presentada en el II Congreso Internacional virtual sobre Desafíos de las Empresas del Siglo XXI. Recuperado de http://www.eumed.net/librosgratis/actas/2017/empresas/13-competitividad-en-empresas-familiares.pdf.

Prieto, P. (2013). Gestión del talento humano como estrategia para retención del personal. (Tesis de grado). Universidad de Medellín, Medellín. Recuperado de https://repository.udem.edu.co/bitstream/handle/11407/160/Gesti\%C3\%B3n\%20del $\% 20$ talento $\% 20$ humano\%20como\%20estrategia\%20para\%20retenci\%C3\%B3n\%20 del\%20personal.pdf?sequence $=1$.

Rigdon, E. (1998). Structural Equation Modeling. In Marcoulides, G. A. (ed.), Modern Methods for Business Research (pp. 251-294). Mahwah, United States: Eribaum.

Rivera, G. e Israel, S. (2013). Modelo de gestión para las empresas familiares con perspectivas de crecimiento y sostenibilidad. Perspectivas, (31), 87-132. Recuperado de https://www.redalyc.org/pdf/4259/425941261003.pdf.

Rodríguez, W. D. (2015). Dificultades de las mipymes en la conformación de alianzas estratégicas. (Monografía de grado). Universidad de Cartagena, Cartagena. Recuperado de http://repositorio.unicartagena.edu.co/handle/11227/2436.

Saavedra, M. (2012). Hacia la competitividad de la pyme latinoamericana. Macroproyecto de investigación. $\quad$ Recuperado de http://www.alafec.unam.mx/docs/macroproyectos/competitividad_macro.pdf.

Sánchez, M. y Jiménez, D. (2013). La validez del instrumento de medida. En Sarabia, F. J. (coord.), Métodos de Investigación social y de la empresa (pp. 387-420). Madrid, España: Pirámide.

Sánchez, S. y Herrera, M. (2016). Los recursos humanos bajo el enfoque de la teoría de los recursos y capacidades. Revista de la Facultad de Ciencias Económicas, 24(2), 133146. Recuperado de http://dx.doi.org/10.18359/rfce.2216. 


\section{Pic}

REVISTA IBEROAMERICANA DE CONTADURÍA, ECONOMÍA YADMINISTRACIÓN

ISSN $=2007-9907$

Soto, A. (2013). La empresa familiar en México. Situación actual de la investigación. Contaduría y Administración, 58(2), 135-171.

Valenzuela, M. M., López, V. G. y Moreno, L. R. (2015). La planeación estratégica como factor de competitividad en las empresas familiares del sector comercial del valle de Mexicali. European Scientific Journal, 11(1), 1857-7881.

Vallejo, M. (2011). The organizational culture of family firms as a key factor of competitiveness. Journal of Business Economics and Management, 12(3), 451-481. Retrieved from https://doi.org/10.3846/16111699.2011.599407.

Vanoni, G., y Pérez, M. (2015). Protocolos: un instrumento para mediar conflictos en empresas familiares. Desarrollo Gerencial, 7(2), 81-99. Recuperado de http://revistas.unisimon.edu.co/index.php/desarrollogerencial/article/view/438.

Ward, J. (2004). Perpetuating the Family Business. United Kingdom: Palgrave Macmillan.

Wright, S. (1923). The Theory of Path Coefficients: A Reply to Niles`s Criticism. Genetics, $8,239-255$. 


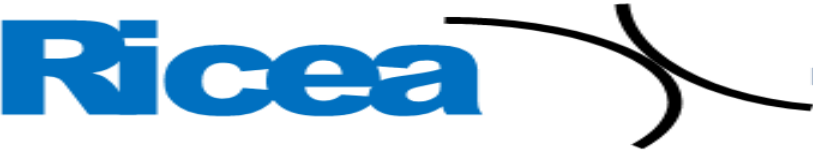

REVISTA IBEROAMERICANA DE CONTADURÍA, ECONOMIIA YADMINISTRACIÓN

ISSN : $2007-9907$

\begin{tabular}{|c|c|}
\hline Rol de Contribución & Autor (es) \\
\hline Conceptualización & Gloria Muñoz del Real (principal); Alma Delia Inda (igual). \\
\hline Metodología & Alma Delia Inda (principal); Gloria Muñoz del Real (igual) \\
\hline Software & Alma Delia Inda (principal); Gloria Muñoz del Real (igual) \\
\hline Validación & Alma Delia Inda (principal); Gloria Muñoz del Real (igual) \\
\hline Análisis Formal & Alma Delia Inda (principal); Gloria Muñoz del Real (igual) \\
\hline Investigación & Gloria Muñoz del Real (principal); Alma Delia Inda (igual); \\
\hline Recursos & Gloria Muñoz del Real (principal); Alma Delia Inda (igual); \\
\hline Curación de datos & Gloria Muñoz del Real (principal); Alma Delia Inda (igual); \\
\hline $\begin{array}{l}\text { Escritura - Preparación del } \\
\text { borrador original }\end{array}$ & $\begin{array}{l}\text { Gloria Muñoz del Real (principal); Alma Delia Inda (igual); } \\
\text { Olga Lidia Gutierrez Gutierrez (apoya). }\end{array}$ \\
\hline $\begin{array}{l}\text { Escritura - Revisión y } \\
\text { edición }\end{array}$ & $\begin{array}{l}\text { Alma Delia Inda (principal); Gloria Muñoz del Real (igual); } \\
\text { Olga Lidia Gutierrez Gutierrez (apoya). }\end{array}$ \\
\hline Visualización & $\begin{array}{l}\text { Alma Delia Inda (principal); Gloria Muñoz del Real (igual); } \\
\text { Olga Lidia Gutierrez Gutierrez (que apoya). }\end{array}$ \\
\hline Supervisión & Gloria Muñoz del Real (principal); Alma Delia Inda (igual); \\
\hline Administración de Proyectos & Gloria Muñoz del Real (principal) \\
\hline Adquisición de fondos & Alma Delia Inda (principal) \\
\hline
\end{tabular}

